\title{
Job satisfaction among Malaysian school counselors
}

\begin{abstract}
The purpose of this study was to identify the level of job satisfaction among school counsellors in Malaysia and factors related to it. The findings uncover moderate level of job satisfaction of school counsellors with mean: 3.52 and S.D : 0.59. Job satisfaction among school counsellors was categorized as satisfaction with rewards, satisfaction with the job itself, satisfaction with leadership of the superior, and satisfaction with co-workers. School counsellors' job satisfaction has been associated with various aspects such as ethnicity and student numbers in the school.
\end{abstract}

Keyword: School Counselors, Job Satisfaction 